\section{KẾT LUẬN}

Số lượng chân răng 2 bên phải và trái khác biệt nhau không có ý nghĩa thống kê. Răng số 6 hàm dưới thường có 2 chân răng $(88,7 \%)$. Sự khác biệt về số lượng chân răng ở hai giới không có ý nghĩa thống kê.

Chân gần răng số 6 hàm dưới chủ yếu có 2 ống tủy riêng biệt kéo dài từ buồng tuỷ tới chóp chân răng (Vertucci IV) chiếm 55,6\%. Sự khác nhau bên phải và trái cũng như sự khác nhau giữa nam và nữ là không có ý nghĩa thống kê.

Chân xa răng số 6 hàm dưới chủ yếu có 1 ống tủy kéo dài từ buồng tuỷ tới chóp chân răng (Vertucci I) chiếm $77,1 \%$. Sự khác nhau bên phải và trái cũng như sự khác nhau giữa nam và nữ là không có ý nghĩa thống kê.

\section{TÀI LIÊU THAM KHẢO}

1. $\mathrm{Na} \mathrm{Ni}$, Shen Cao, Lei Han et al., Cone-beam computed tomography analysis of root canal morphology in mandibular first molars in a Chinese population: a clinical studay. Evidence-Based Endodontics, $2018.23: 1$ (https://doi.org/10.1186/s41121-018-0015-8).

2. Ozkan Miloglu, Hakan Arslan, Cagatay Barutcigil et al., Evaluating root and canal configuration of mandibular first molars with cone beam computed tomography in a Turkish population. Journal of Dental Sciences, 2013. 8, p. 80-86 (http://dx.doi.org/10.1016/j.jds.2012.09.002).

3. Hiên, H.H.T., Đắc Điểm Hình Thái Chân Răng Và Ông Tủy Răng Cối Lớn Thứ Nhất Và Thứ Hai Người Việt Nam. Luận án Tiến sĩ, trường Đại Học Y Dược TP Hồ Chí Minh, 2019.

4. Bansal, R., S. Hegde, and M.S. Astekar, Classification of Root Canal Configurations: A Review and a New Proposal of Nomenclature System for Root Canal Configuration. Journal of Clinical and Diagnostic Research, 2018 (https://doi.org/10.7860/jcdr/2018/35023.11615).

5. Vertucci F.J., Root canal morphology and its relationship to endodontic procedures. Endodontic Topics, 2005. 10, : p. 3-29 (https://doi.org/ 10.1111/j.1601-1546.2005.00129.x).

6. Shehadat S.A., Waheb S., Bayatti S.W.A et al., Cone beam computed tomography analysis of Root and Root canal Morphology of First permanent lower molars in a Middle East Subpopulation. Journal of International Society of Preventive \& Community Dentistry, 2019. 9(5). p: 458-463.

7. Sharaan M.E., Elrawdy A.M., An evaluation of mandibular molars root canal morphology using cone-beam computed tomography in an Egyptian subpopulation. Tanta Denatal Journal, 2017. 14, p: 220-224 (https://doi.org/10.4103/tdj.tdj_50_17).

\title{
ĐĂC ĐIỂM TỔN THƯƠ'NG VÕNG MẠC TRÊN BỆNH NHÂN ĐÁI THÁO ĐƯỜNG LỌC MÁU CHU KÌ
}

Vũ Tuấn Anh*

\section{TÓM TẮT}

Mục tiêu: Mô tả đăc điểm lâm sàng của tổn thương võng mạc trên bệnh nhân bị bệnh đái tháo đường (ĐTĐ) đang lọc máu chu kì. Đối tượng và phương pháp nghiền cứu: nghiên cưú mô tả trên 63 bệnh nhân ĐTÐ đang lọc máu chu kỳ (126 mắt), thu thập các thông tin cơ bản (tuổi, giới, thời gian mắc ĐTÐ, typ ĐTÐ, thời gian lọc máu ...), khám đáy mắt và chụp ảnh võng mạc kỹ thuật số tiêu chuẩn xác định tổn thương của bệnh võng mạc ĐTĐ và tổn thương phối hợp . Kết quả: tuổi bệnh nhân trung bình 54士 9,7 (23-77); nam giới chiếm $65,1 \%$; đa số số mắt đều có thị lực giảm 89,5\% (113/126); hâuu hết mắc bệnh võng mạc ĐTĐ (125/126 mắt), trong đó giai đoạn chưa tăng sinh nhe và vừa là $65,9 \% \%$ (83 mắt), tiền tăng sinh $20,6 \%$ (26 mắt) và tăng sinh $12,7 \%$ (16 mắt), tỷ lệ phù hoàng điểm 19,8\% (25 măt). Kết luận: tổn thương võng mạc của bệnh

*Bệnh viện Mắt trung ương.

Chịu trách nhiệm chính: Vũ Tuấn Anh

Email: vta.oph@gmail.com

Ngày nhận bài: 16.3.2021

Ngày phản biên khoa học: 14.5.2021

Ngày duyệt bài: 21.5.2021 nhân ĐTĐ có lọc máu chu kì là rất nặng và có nhiều tổn thương phối hợp, vì vậy việc khám võng mạc có chụp ảnh võng mạc không thuốc cản quang sớm và định kỳ có thể giúp phát hiện và can thiệp sớm các biến chứng năng ở mắt.

Tư khóa: bệnh võng mạc đái tháo đường, lọc máu chu kỳ

\section{SUMMARY}

RETINAL LESION FEATURES OF HEMODIALYSIS

PATIENTS WITH DIABETES MELLITUS

Purpose: Descibe the retinal lesion features in patients with diabetes mellitus on hemodialysis. Materials and Methods: observational study, 126 eyes of 63 diabetes patients on hemodialysis, grading for retinal lesion $(R 0 \rightarrow R 4)$, macular lesion (M0, M1) following the criteria of the ICO classification and find out other retinal lesions. Results: demography: age average $54 \pm 9.7(23-77), 65.1 \%$ were male, majority of eyes has vision impairment $89,5 \%(113 / 126)$; almost had DR (125/126) included R1-R2 65.9\%, R3 20.6\%, R4 $12.7 \%$ and macular edema (M1) prevalence was $19.8 \%$. Conclusion: prevalence of DR in DM on hemodialysis group was remarkable, so the DR screening by eye check and digital fundus camera scan for this special group would be necessary. 
Keyword: diabetic retinopathy, hemodialysis

\section{I. ĐĂT VẤN ĐỀ}

Thời gian sống của bệnh nhân đái tháo đường (ĐTÐ) phải lọc máu chu kì tăng lên rõ rệt, do kĩ thuật lọc thận ngày càng được cải thiện $n^{1,2,3}$. Thời gian gẩn đẩy, tỷ lệ nguyên nhân gầy suy thận phải lọc máu chu kì do ĐTĐ tăng mạnh ở các nước phát triển cũng như tại Việt Nam³. Tuy vậy, bệnh võng mạc ĐTÐ còn chưa được tìm hiểu nhiều trên nhóm bệnh nhân lọc máu chu kỳ. Đây là nhóm bệnh nhân nặng, có nhiều khó khăn trong theo dõi và điều trị, đặc biệt là chống chỉ định trong chụp mạch huỳnh quang ${ }^{5}$.

Tổn thương tại mắt tuy không đe dọa đến chức năng sống nhưng lại gây giảm chất lượng sống trầm trọng. Khám phát hiện sớm các tổn thương võng mạc do đái tháo đường và các tổn thương võng mạc phối hợp khác có thể giúp can thiệp sớm, tránh các biển chứng nặng tại mắt đòi hỏi phải can thiệp bằng các phẫu thuật chảy máu - rất khó khăn trên nhóm bệnh nhân có sử dụng thuốc chống đông liên tục này.

Vì vậy, chúng tôi bước đầu tiến hành nghiên cứu này mục tiêu: Mô tả đặc điểm lâm sàng của tổn thương vông mạc trên bệnh nhân bị bệnh đái tháo đường đang lọc máu chu ki.

\section{II. ĐỐI TƯỢNG VÀ PHƯƠNG PHÁP NGHIÊN CỨU}

2.1. Đối tượng nghiên cứu. Các bệnh nhân đã được chẩn đoán ĐTÐ đang điều trị lọc máu chu kì đến khám tại Bệnh viện Mắt trung ương từ 9/2019 đến 8/2020.

Tiêu chuẩn lựa chọn bệnh nhân: là tất cả những bệnh nhân đã được chẩn đoán xác định ĐTĐ đang điều trị lọc máu chu kì, đồng ý tham gia nghiên cứu.

Tiêu chuẩn loại trừ: bệnh nhân quá yếu, khó hợp tác; bệnh nhân bị đục nhiều môi trường trong suốt của mắt ở mức độ cản trở soi đáy mắt (sẹo giác mạc, đục thủy tinh thể độ 4 , xuất huyết dịch kính +++ ), khó giãn đồng tử.

2.2. Thiết kế và qui trình nghiên cứu. Nghiên cứu mô tả cắt ngang,

Thu thập các thông tin cơ bản: tuổi, giới, typ ĐTÐ, thời gian mắc bệnh ĐTĐ, thời gian lọc thận.

\section{Khám măt}

- Thử thị lực có chỉnh kính với bảng thị lực Snellen, phân loại thị lực theo quy định của Tồ chức y tế thế giới (WHO) năm 1985.

- Khám bán phần trước thường quy: giác mạc, tiền phòng, mống mắt

- Khám phát hiện tổn thương bán phần sau: sau khi nhỏ giãn đồng tử tối đa k,hám đáy mắt bằng kính Volk $+90 \mathrm{D}$ kết hợp với sinh hiển vi khám bệnh phát hiện các tổn thương võng mạc

- Xác định các tổn thương võng mạc

Xác định giai đoạn bênh võng mạc ĐTÐ

\begin{tabular}{|c|c|}
\hline Không mắc bệnh & R0 \\
\hline Không tăng sinh - nhè & R1 \\
\hline Không tăng sinh - vừa & R2 \\
\hline Không tăng sinh - nănng & R3 \\
\hline Tăng sinh & R4 \\
\hline Phù hoàng điểm / không phù & M1 / M0 \\
\hline
\end{tabular}

- Xác định các bệnh phối hợp: tắc tĩnh mạch, tắc động tînh mạch, sẹo hoàng điểm, teo gai thị

Khám toàn thân: huyết áp, đường máu, HbA1c, lipid máu, creatinin máu.

Đạo đức nghiên cứu. Nghiên cứu tuân thủ các qui tắc đạo đức trong nghiên cứu $Y$ sinh học, được thông qua Hội đồng đạo đức và được mã hóa, giữ bí mật thông tin của bệnh nhân.

Các bệnh nhân đều được tư vấn về quá trình theo dõi điều trị của mình, và đều được theo dõi định kì sau nghiên cứu.

\section{KẾT QUẢ NGHIÊN CỨU VÀ BÀN LUẬN}

Trong thời gian nghiên cứu từ tháng 9/2019 đến $8 / 2020$, chúng tôi tiến hành nghiên cứu, thu nhập số liệu và khám 126 mắt của 63 bệnh nhân

\section{1. Đặc điểm của bệnh nhân.}

3.1.1. Tuổi, giới, typ ĐTĐ

Tỷ lệ bệnh nhân nam chiếm 65,1\% (41/63)

Trong số 63 bệnh nhân nghiên cứu có 12 bệnh nhân bị ĐT Đ type 1, chiếm 19\%.

Tuổi trung bình của nhóm đối tượng nghiên

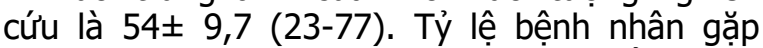
nhiều nhất là những người trong độ tuổi từ 50 60 tuổi, chiếm tới $55 \%$, còn nêu tính những người $\leq 60$ tuổi thì tỷ lệ này chiếm tới $71,4 \%$.

Đặc điểm về tuổi của nhóm đối tượng nghiên cứu của chúng tôi có nhiều khác biệt với các nghiên cứu về bệnh võng mạc ĐTĐ trong cộng đồng với nhóm đối tượng nghiên cứu của tác giả Hoàng Thị Phúc ${ }^{8}$, với tỷ lệ bệnh nhân dưới 60 tuổi là 45,4\%, của tác Trần Minh Tiến ${ }^{7}$ là $62,1 \%$, của Nguyễn Thị Ngọc Hân ${ }^{4}$ là $42,3 \%$. Có thể nói là tuổi của nhóm lọc thận thấp rất đáng chú ý so với nhóm bệnh nhẩn ĐṬĐ ngoài cộng đồng.

\subsubsection{Thời gian mắc bệnh đái tháo đường}

Bảng 3.1. Thời gian mắc ĐTÐ

\begin{tabular}{|c|c|c|}
\hline Thời gian & Số lượng & Tỷ lệ (\%) \\
\hline$\leq 5$ năm & 2 & 3,1 \\
\hline $5-\leq 10$ năm & 6 & 9,5 \\
\hline $10-\leq 15$ năm & 30 & 47,7 \\
\hline$>15$ năm & 25 & 39,7 \\
\hline
\end{tabular}

Bệnh nhân chủ yếu có thời gian mắc ĐTĐ > 10 năm. Điều này phù hợp với tiến triển về mức độ nặng của các biến chứng vi mạch. Số bệnh 
nhân có thời gian mắc $Đ T Ð \leq 10$ năm chủ yếu là ĐTÐ typ 1, hoặc ĐTĐ typ 2 nhưng có tiên sử kém kiểm soát bệnh lý toàn thân.

3.1.3. Thời gian chạy thận. Thời gian chạy thận (lọc máu chu kì) của nhóm bệnh nhẩn nghiên cứu là $12 \pm 6,9$ tháng (3-60 tháng). Bệnh nhân chạy thận sớm nhất là 3 tháng là bệnh nhân 54 tuổi mắc ĐTĐ typ 2 phát hiện muộn. Thời gian này có xu hướng kéo dài ở các nước phát triển vì khả năng phát hiện và quản lý bệnh ĐTĐ sớm hơn so với ở Việt Nam.

3.2. Đắc điểm bênhh võng mạc đái tháo đường và 1 số tổn thương vṍng mạc khác

3.2.1. Tôn thương vông mạc ĐTt

Bảng 3.2. Các tốn thương vông mạc ĐTÐ

\begin{tabular}{|c|c|c|}
\hline Tổn thương & $\begin{array}{c}\text { Số măt } \\
(\mathrm{n}=126)\end{array}$ & $\begin{array}{c}\text { Tỷ lệ } \\
\mathbf{( \% )}\end{array}$ \\
\hline Vi phình mạch & 125 & 99,2 \\
\hline Xuất huyết võng mạc & 51 & 40,5 \\
\hline Xuất tiết cứng & 112 & 88,9 \\
\hline Xuất tiết bông & 39 & 71,4 \\
\hline Phù hoàng điếm & 25 & 19,8 \\
\hline Biến đối mạch máu & 21 & 16,7 \\
\hline Xuất huyết dịch kính & 6 & 4,8 \\
\hline Bong võng mạc co kéo & 2 & 1,6 \\
\hline Tân mạch & 15 & 11,9 \\
\hline
\end{tabular}

Bảng 3.3. Giai đoan bênh vông mac ĐTÐ

\begin{tabular}{|c|c|c|}
\hline Giai đoạn & $\begin{array}{c}\text { Số } \\
\text { mắt }\end{array}$ & $\begin{array}{c}\text { Tỷ lệ } \\
(\mathbf{\%})\end{array}$ \\
\hline Không có bệnh VM ĐTĐ (R0) & 1 & 0,8 \\
\hline Giai đoạn nền (R1-R2) & 83 & 65,9 \\
\hline Tiền tăng sinh (R3) & 26 & 20,6 \\
\hline Tăng sinh (R4) & 16 & 12,7 \\
\hline Tống & $\mathbf{1 2 6}$ & $\mathbf{1 0 0}$ \\
\hline Phù hoàng điếm & $\mathbf{2 5}$ & $\mathbf{1 9 , 8}$ \\
\hline
\end{tabular}

(Tốn thương phù hoàng điểm là bệnh lý đặc trưng, gặp ở bất kỳ giai đoạn nào của bệnh võng mạc ĐTÐ).

Tỷ lệ biến chứng võng mạc ĐTÐ nặng (R3R4) chiếm $34,5 \%$, tuy nhiên tỷ lệ phù hoàng điểm $(19,8 \%)$ và các tổn thương phối hợp khác gây đe dọa thị lực khá cao (xem bảng 3.4). Các tỳ lệ này cao hớn nhiều so với các nghiên cứu khác trên người (ĐTĐ) không lọc thận.

Bảng 3.4. Các tôn thương vông mạc khác

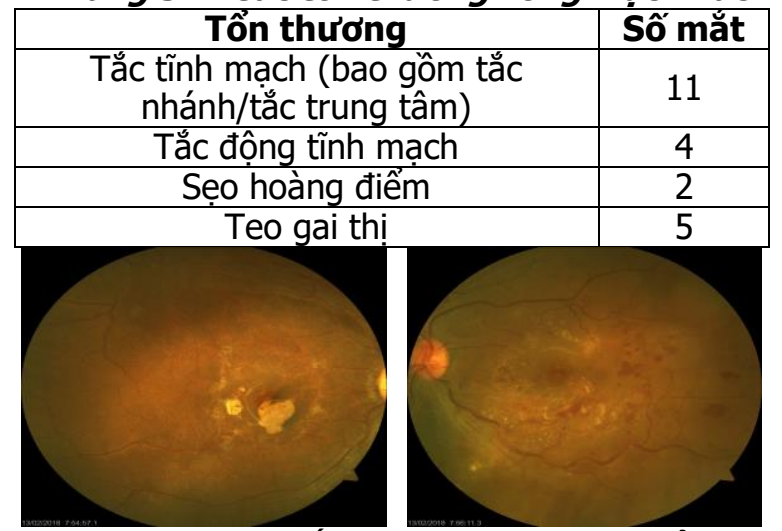

Hình ảnh đáy mắt của BN nam 23 tuối, lọc thận 3 năm, DTÐ typ 1

Trong nhóm bệnh nhân nghiên cứu, có duy nhất 1 bệnh nhẩn có 1 mắt không có tổn thương, mắt còn lại có rất ít vi phình mạch (R1) là bệnh nhân trung niên, có thời gian lọc thận 12 tháng nhưng đã ghép thận thành công. Trong nhóm bệnh nhân nghiên cứu, có 6 mắt xuất huyết dịch kính, 2 mắt bong võng mạc co kéo. Những trường hợp này có chỉ định phẫu thuật, tuy nhiên đây là thách thức lớn vì là phẫu thuật có chảy máu, cần phải dừng thuốc chống đông trước mổ.

Trong nghiên cứu có gặp 5 mắt có biểu hiện teo gai thị, nằm trong bệnh cảnh tăng huyết áp nặng, kéo dài. Bệnh lý tăng huyết áp cũng lý giải sự xuất hiện phổ biến biến chức tắc mạch bao gồm tắc tĩnh mạch võng mạc và tắc động tĩnh mạch. Tăng huyết áp cũng làm thúc đẩy tiến triển các tổn thương bệnh võng mạc ĐTĐ. 2 trường hợp sẹo hoàng điểm là do xuất tiết cứng đọng nhiều và kéo dài ở dưới võng mạc vùng hoàng điểm, khi tiêu đi để lại sẹo, là tổn thương không hồi phục.

\subsubsection{Phân bố mức độ tổn hại thị lực}

\section{Bảng 3.5. Mối liên quan giứa tinh trạng thị lực và giai đoạn bệh vông mạc ĐTÐ}

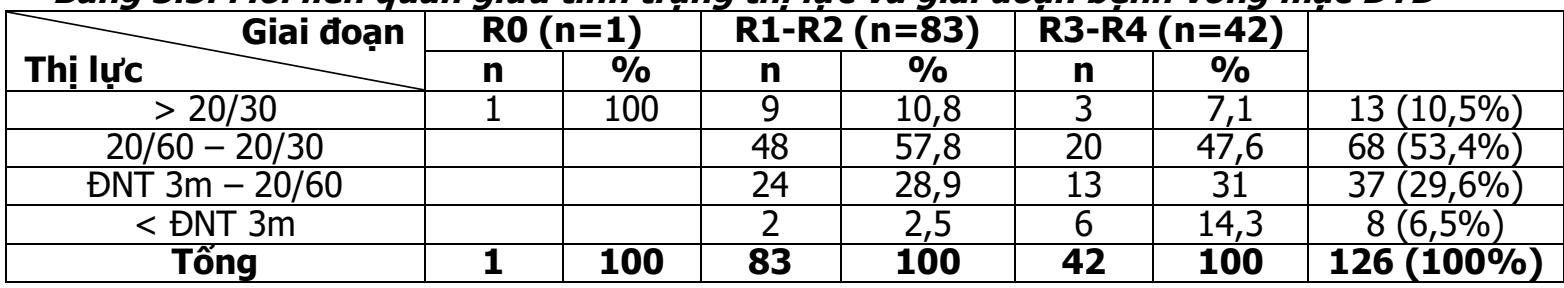

Đa số các mắt đều có suy giảm thị lực $(89,5 \%)$. Mắt duy nhất chưa có tổn hại võng mạc cũng có thị lực tốt (20/20). Đáng chú ý là nhóm suy giảm thị lực nặng ngoài nguyên nhân là tổn hại võng mạc (do ĐTĐ và không do ĐTĐ), còn có nguyên nhân lớn nữa là đục thể thủy 
tinh. Tỷ lệ đục thể thủy tinh là đáng kể trong nhóm bệnh nhân mắc ĐTĐ. Tuy nhiên, nguyên nhân này có thể khắc phục được tương đối dễ dàng, nhanh chóng bằng phẫu thuật thể thủy tinh, đặc biệt là với kỹ thuật mổ gây tê bề mặt (topical anesthesia), không gây chảy máu nền không cần dừng thuốc chống đông trước mổ' .

\section{KẾT LUÂ̂N}

Tổn thương võng mạc trên bệnh nhân ĐTÐ phải lọc máu chu kỳ rất đa dạng, bao gồm các tổn thương của bệnh võng mạc ĐTĐ từ nhẹ tới nặng và cả các tổn thương phối hợp khác (tắc tĩnh mạch, teo gai thị ...), gây giảm thị lực trầm trọng. Tỷ lệ tổn thương nặng cũng cao hơn hẳn so với nhóm bệnh nhân ĐTĐ ở cộng đồng. Vì vậy việc quan tầm theo dõi định kỳ và có chiến lược thăm khám đặc biệt so với các bệnh nhân ĐT̄Đ khác nhằm cải thiện chất lượng sống cho nhóm bệnh nhân đặc biệt này. Nghiên cứu trong thời gian tới sẽ tìm hiểu sâu hơn mối liên quan giữa thời gian chạy thận, các biến chứng toàn thân khác (THA, thiếu máu, suy vành, TBMN ...), các maker đặc biệt (CPR, Apolipoprotein, HbA1c ...) với tiến triển bệnh võng mạc ĐTĐ.

\section{TÀI LIÊUU THAM KHẢO}

1. M. Müller, C. L. Schönfeld, T. Grammer, V. Krane et al. Risk factors for retinopathy in hemodialysis patients with type 2 diabetes mellitus. Nature, 2020;10(1):1415-8.

2. The Vision loss Expert Group of the Global Burden of Disease Study. Global estimates on the number of people blind or visually impaired by diabetic retinopathy: a meta-analysis from 1990 to 2010. Diabetes Care, 2016;39, 1643-1649.

3. Connie M Rhee, Angela M Leung, Csaba P Kovesdy et al. Úpdates on the management of diabetes in dialysis patients. Semin Dial, 2014;27(2):135-45

4. Nguyễn Thị Ngọc Hân. Nghiên cứu tình hình tổn thương võng mạc trên bệnh nhân đái tháo đường tại Bệnh viện đa khoa Phúc Yên, Luận văn tốt nghiệp bác sỹ chuyên khoa cấp II, Trường Đại học Y Hà nội; 2017

5. Klein R., Knudtson M. D., Lee K. E. et al. The Wisconsin Epidemiologic Study of Diabetic Retinopathy: XXII the twenty-five-year progression of retinopathy in persons with type 1 diabetes. Ophthalmology, 2008; 115(11), 1859-1868.

6. Lee $R$, Wong TY, Sabanayagam $C$ Epidemiology of diabetic retinopathy, diabetic macular edema and related vision loss. Eye and vision. 2015;2(1):1-25.

7. Trân Minh Tiến. Nghiên cứu một số đặc điểm dịch tễ học và lâm sàng bệnh võng mạc đái tháo đường tại bệnh viện, Luận văn tốt nghiệp bác sỹ chuyên khoa cấp II, Trường Đại học Y Hà nội; 2006

8. Hoàng Thị Phúc và cs. Ứng dụng các phương pháp phát hiện sớm bệnh lý võng mac ở bệnh nhân đái tháo đường và các phương pháp điều trị. Đề tài nghiên cứu khoa học cấp bộ, Bộ Y tế; 2012

\section{HIỆU QUẢ CAN THIÊPP CẢI THIÊNN THỰC HÀNH DINH DƯỠNG VÀ TUẦ THỦ SỬ DƯNG THUỐC ĐIỂU TRİ CỦA BỀNH NHÂN ĐÁI THÁO ĐƯỜNG TUÝP 2 NGOẠI TRÚ TẠI BỆNH VIỆN ĐA KHOA NÔNG NGHỆP}

\section{TÓM TẮT}

Mục tiêu: Đánh giá hiệu quả can thiệp cải thiện thực hành dinh dưỡng và tuân thủ sử dụng thuốc điểu trị của bệnh nhân ĐTĐ týp 2, ngoại trú tại Bệnh viện Đa khoa Nông nghiệp (2016-2017). Phương pháp: Mô tả cắt ngang; can thiệp giáo dục sức khỏe trực tiếp thông qua các buổi sinh hoạt câu lạc bộ giáo dục phòng chống ĐTÐ của Bệnh viện nhằm nâng cao kiển thức, thực hành về dinh dưỡng, luyện tâp thể lực, tuân thư dùng thuốc trong điều trị và kiểm soát đường máu, khám bệnh định kỳ cho bệnh nhân. Đánh giá

\footnotetext{
*Bệnh viện Đa khoa Nông nghiệp

**Hoc viên Quân y Viêt Nam

Chịu trách nhiệm chính: Tống Lê Văn

Email: vanbvnn@yahoo.com

Ngày nhận bài: 15.3.2021

Ngày phản biên khoa học: 12.5 .2021

Ngày duyệt bài: 18.5.2021
}

\section{Tống Lê Văn*, Hoàng Hải**}

thực hành về dinh dưỡng và tuân thủ sử dụng thuốc điểu trị của đối tượng can thiệp bằng bảng hỏi kết hợp phân tích số liệu thứ cấp trong hồ sơ bệnh án của bểnh nhân; tính CSHQ. Kết quả: Hiệu quả cải thiện sử dụng các loại thực phẩm thường xuyên hàng ngày theo chiêuu hướng tốt cho người ĐTĐ như: ăn phân cơm mô̂i bữa tương đương 45-65g tinh bột đã tăng từ $58,9 \%$ lên $74,1 \%(p<0,001)$. Ăn rau xanh $\geq 5$ đơn vị chuẩn/ngày tăng từ $25,0 \%$ lên $76,4 \%$ (CSHQ = $205,6 \%$ ). An quả chín tữ $\geq 2$ giờ sau bữa ăn chính tăng từ 41,2\% lên 80,2\% (CSHQ=94,7\%). Ăn các loại thịt giảm nhưng ăn các loại thực phẩm 3-4 lần/tuần như cá, hải sản, đậu phu, các loại đạu/đỗ, lạc/vững có Iợi cho người ĐTĐ đều tăng sau can thiệp. Việc tuân thủ sử dụng thuốc điều trị được cải thiện rõ rệt, từ $84,6 \%$ lên $98 \%(\mathrm{CSHQ}=15,8 \%)$. Kết luẩn: Hiẹu quả cải thiên sử dụng các loại thực phẩm tốt cho người ĐTĐ tăng lên rỗ rệt sau can thiệp; các loại thực phẩm không tốt cho người ĐTĐ đã giảm đáng kể. Hiêu quả tuân thủ dùng thuốc trong điêu trị được cải thiện rõ 